\title{
Dynamic deformation and fault locking of the Xianshuihe Fault Zone, Southeastern Tibetan Plateau: implications for seismic hazards
}

\author{
Layue $\mathrm{Li}^{1}$, Yanqiang $\mathrm{Wu}^{1 *}{ }^{*}$, Yujiang $\mathrm{Li}^{2}$, Wei Zhan ${ }^{1}$ and Xinzhong Liu ${ }^{1}$
}

\begin{abstract}
The Xianshuihe Fault Zone is one of the most historically seismically active regions in mainland China. However, the seismicity along this fault zone has been quiescent for the past 40 years, since the Daofu M6.9 earthquake in 1981. Understanding its current deformation patterns and fault coupling characteristics is of great significance to estimate the potential risk of strong earthquakes. In this study, we analyzed the dynamic deformation and fault coupling characteristics along the Xianshuihe Fault Zone using Global Navigation Satellite System (GNSS) data for 1999-2007 and 2016-2020. The results show that the deformation pattern of the Xianshuihe fault zone underwent a dynamic adjustment after the 2008 Wenchuan $M_{w} 7.9$ and 2013 Lushan $M_{w} 6.6$ earthquakes, i.e., the maximum shear strain accumulation rates of the Luhuo and Daofu sections significantly decreased from $6.0 \times 10^{-8} / \mathrm{a}$ to $3.2 \times 10^{-8} / \mathrm{a}$, while that of the southeastern segment (i.e., Kangding and Moxi sections) increased from $4.5 \times 10^{-8} / \mathrm{a}$ to $6.2 \times 10^{-8} / \mathrm{a}$. Additionally, the slip rate and deformation width of the Xianshuihe Fault Zone also changed during these two periods. Combined with the near-field cross-fault observation data, we suggest that the surrounding strong earthquakes Wenchuan and Lushan had evident differential impacts on the deformation pattern of the Xianshuihe Fault Zone. The fault-coupling inversion results show that the locking degree of the Xianshuihe Fault Zone continued to increase after the Wenchuan and Lushan earthquakes, especially the Qianning and Moxi sections increased significantly, with an average coupling coefficient of greater than 0.9 and left-lateral slip-rate deficits of $\sim 5 \mathrm{~mm} / \mathrm{a}$ and $\sim 8 \mathrm{~mm} / \mathrm{a}$, respectively. In contrast, the locking degree of the Kangding section decreased with almost no slip-rate deficit, which is in a state of creeping status. The analysis of the recent rupture history and strain accumulation characteristics of the Xianshuihe Fault Zone indicates that both the Qianning and Moxi sections have a high seismic potential for the next strong earthquake in the Xianshuihe Fault Zone.
\end{abstract}

Keywords: Xianshuihe Fault Zone, Strain rate accumulation, Fault locking degree, Slip-rate deficit, Seismic hazards

\section{Introduction}

The Xianshuihe Fault Zone, located in the southeastern margin of the Tibetan Plateau, is a block boundary fault that plays a significant role in accommodating the Late Cenozoic crustal deformation of the eastern Tibetan Plateau (Wang et al. 1998; Tapponnier et al. 1982; Avouac and Tapponnier 1993). This fault is characterized by a

\footnotetext{
*Correspondence: chdqyw@126.com

${ }^{1}$ The First Monitoring and Application Center, CEA, Tianjin 300180, China Full list of author information is available at the end of the article
}

high left-lateral strike-slip rate and frequent seismic activity. Neotectonic and geodetic studies have estimated that the left-lateral slip on the northwestern and southeastern segments of the Xianshuihe Fault are approximately $15 \pm 5 \mathrm{~mm} / \mathrm{a}$ and $5-9 \mathrm{~mm} / \mathrm{a}$ (Allen et al. 1991; Gan et al. 2007; Wang et al. 2009; Wang and Shen 2020; Ji et al. 2020). In the past $~ 300$ years, at least eight $M \geq 7.0$ earthquakes and fifteen $M \geq 6.5$ earthquakes initiated in the Xianshuihe Fault Zone (Wen et al. 2008; Yi et al. 2015). However, the strong seismic activity on the Xianshuihe Fault Zone has been relatively quiescent 
for $\sim 40$ years, with only two moderate earthquakes, the $M_{\mathrm{w}} 5.9$ and $M_{\mathrm{w}} 5.6$ Kangding earthquakes in 2014. In contrast, a series of strong earthquakes have successively occurred along the other boundary faults around the Bayan Har Block, including the $M_{\mathrm{w}} 7.8$ Kunlun Pass earthquake in 2001, the $M_{\mathrm{w}} 7.9$ Wenchuan earthquake in 2008, and the $M_{\mathrm{w}} 6.9$ Yushu earthquake in 2010 (Deng et al. 2015). Large earthquakes can modulate the crustal deformation, stress field, and strain accumulation of the surrounding faults (King et al. 1994; Stein 2003; Nalbant and McCloskey 2011; Wu et al. 2018). Therefore, the potential seismic hazard posed by the Xianshuihe Fault deserves additional attention.

The strain rate accumulation, fault coupling, and sliprate deficit provide insights into the seismic hazard assessment on faults (Miura et al. 2002; Ader et al. 2012; Riguzzi et al. 2012; Dogru et al. 2018; Weiss et al. 2020). Based on joint inversions of Global Navigation Satellite System (GNSS) and Interferometric Synthetic Aperture Radar (InSAR) data, Jiang et al. (2015) inverted the distribution of the interseismic fault locking of the Xianshuihe-Zemuhe Fault system and found that a potential asperity exists in the Qianning-Kangding section. Guo et al. (2018) inverted the slip rate and the locking degree of the Xianshuihe Fault Zone using GNSS data from 1999 to 2017, and suggested that the Daofu-Kangding section is at high risk for $M_{\mathrm{w}} 6.6$ or greater earthquakes in the future. Using GNSS data from 2004 to 2017, Li et al. (2020a) also inverted the slip-rate deficit and locking degree of the Xianshuihe Fault Zone, and revealed that the Daofu-Qianning section is experiencing creep at the surface, and it will not be able to generate earthquakes with magnitudes of larger than 7.0 in the near future. In contrast, they determined that the Selaha Fault is most likely to generate a $M_{\mathrm{w}}>7$ earthquake. Based on 2014-2019 InSAR images, Qiao and Zhou (2021) and Li and Bürgmann (2021) identified multiple creeping sections along the Xianshuihe fault zone, and concluded that the Qianning section is capable of generating a $M_{\mathrm{w}} 6.6$ or $M_{\mathrm{w}} 6.7$ earthquake. Although these studies agree that the Xianshuihe Fault Zone presents a high seismic hazard, the potential location of the strong earthquakes in the Xianshuihe Fault Zone remains controversial.

The dynamic changes in the crustal movement obtained via geodetic observations not only respond to the rupture process of great earthquakes but also reflect the seismogenic processes of strong earthquakes and the adjustment process after an earthquake, which is essential information for determining the subsequent seismic potentials of large earthquakes (Jiang et al. 2009; Zou et al. 2015; Wu et al. 2018; Zhao et al. 2020). In this study, we focused on the dynamic deformation characteristics of the Xianshuihe Fault Zone using two periods of GNSS observations and estimated the potential seismic hazards it poses. First, we analyzed the characteristics of the historical seismic activity along the Xianshuihe Fault Zone, and then, we analyzed the dynamic deformation characteristics by calculating the strain rate fields and GNSS velocity profiles. Finally, based on the negative dislocation model, we inverted the fault coupling and slip-rate deficit distribution to provide a detailed estimation of the potential seismic hazards posed by the Xianshuihe Fault Zone.

\section{Tectonic setting and seismicity Tectonic setting}

The Xianshuihe Fault Zone is a highly active left-lateral strike-slip boundary fault between the Bayan Har Block and the Sichuan-Yunnan Block within the eastern Tibetan Plateau (Zhang et al. 2003). The Xianshuihe Fault is approximately $400 \mathrm{~km}$ long, strikes $\mathrm{N} 40^{\circ}-50^{\circ} \mathrm{W}$, and has a steep dip angle. It extends from Donggu, Ganzi County in the northwest through Luhuo County, Daofu County, and Kangding County to Shimian County in the south (Qian et al. 1988; Wen et al. 1989; Xu et al. 2003). The Xianshuihe Fault Zone is divided into northwestern and southeastern segments by a geometric discontinuity near the Qianning Basin (Qian et al. 1988). The northwestern segment has a simple fault geometry and consists of the Luhuo, Daofu, and Qianning sections, whereas the structure of the southeastern segment is relatively complicated (Bai et al. 2018). The Kangding section, which extends from the Qianning Basin to Kangding County, consists of three nearly parallel secondary faults, the Yala River, Selaha, and Zheduotang branches. The Moxi section extends from south of Kangding to Shimian county, and the surface trace of this fault is distinct (Fig. 1). The detailed geometry of each fault section is presented in Table 1.

\section{Historic seismic activity}

The Xianshuihe Fault Zone has experienced numerous historic strong earthquakes. Here, we compiled a cata$\log$ of the $M \geq 6.0$ earthquakes during 1700-2020 from two sources, including records of historical earthquakes in China and data from China Earthquake Networks Center. Meanwhile, earthquake rupture data from Wen et al. (2008) were also collected. The magnitude-time frequency diagram and spatiotemporal distribution of the strong earthquake $(M \geq 6.0)$ ruptures in the Xianshuihe Fault Zone are shown in Fig. 2. We identified two seismically active periods, $1700-1816$ and $1893-$ present (Fig. 2a). During 1700-1816, at least nine $M \geq 6.0$ earthquakes occurred in the Xianshuihe Fault Zone, including three $M \geq 7.0$ earthquakes, which led to the rupture of most of the sections of the Xianshuihe Fault Zone 


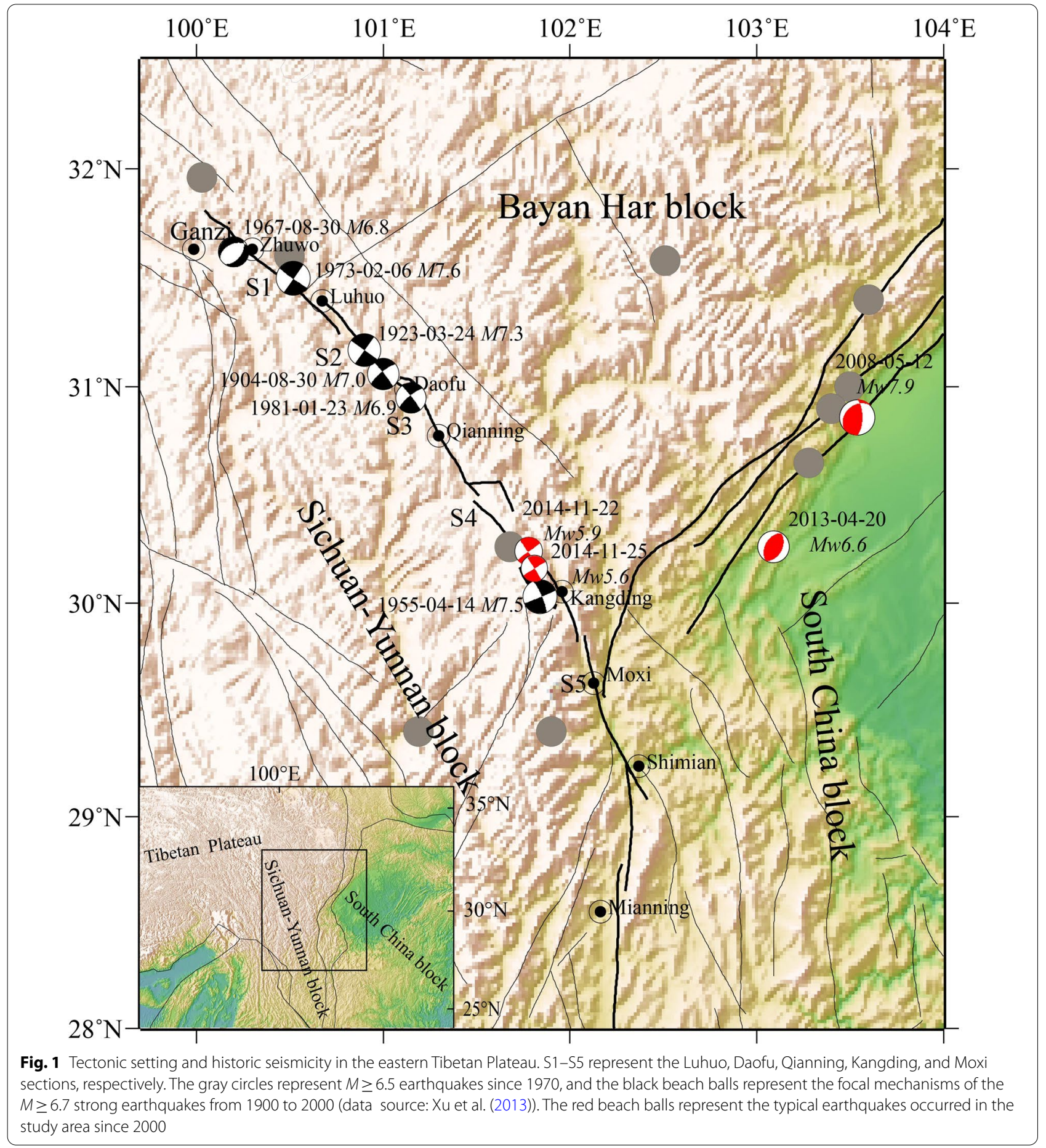

(Fig. 2b). During the second active period, i.e., since 1893, seven $M \geq 6.5$ earthquakes occurred in the Xianshuihe Fault Zone, including five $M \geq 7.0$ earthquakes. However, most of these earthquakes occurred in the northwestern segment. Only the M 7.5 Zheduotang earthquake in 1955 occurred in the Kangding section, and the seismicity in the southeastern segment was sparse. Although the $M_{w} 5.9$ and $M_{w} 5.6$ Kangding earthquakes occurred in 2014, their rupture scales were small, only about $30 \mathrm{~km}$ long (Yi et al. 2015). In addition, there have been no strong earthquakes in the Moxi section since 1786, and 
Table 1 Segmentation and geometric parameters of the Xianshuihe Fault Zone

\begin{tabular}{llll}
\hline Number & Fault section & Strike & Dip \\
\hline S1 & Luhuo & $\mathrm{N} 45^{\circ} \mathrm{W}$ & $\mathrm{NE} 80^{\circ}$ \\
S2 & Daofu & $\mathrm{N} 45^{\circ} \mathrm{W}$ & $\mathrm{NE} 80^{\circ}$ \\
S3 & Qianning & $\mathrm{N} 40^{\circ} \mathrm{W}$ & $\mathrm{NE} 80^{\circ}$ \\
S4 & Kangding & $\mathrm{N} 30^{\circ} \mathrm{W}$ & $\mathrm{NE70}$ \\
S5 & Moxi & $\mathrm{N} 20^{\circ} \mathrm{W}$ & $\mathrm{NE70}$ \\
\hline
\end{tabular}

234 years have passed since the last earthquake. Thus, the seismicity of this section is also worthy of attention.

\section{Data and methods}

\section{Data collection and processing}

The GNSS data used in this study were collected from the Crustal Movement Observation Network of China (CMONOC I) and the Tectonic and Environmental Observation Network of Mainland China (CMONOC II). Most of the stations have operated for over 10 years or have had at least five observational campaigns with the campaign sites being observed for 4 days during each campaign, which allowed us to obtain high-accuracy velocities. In general, the crustal deformation recorded by the GNSS stations not only contains interseismic tectonic motion, but also the co- and post-seismic effects associated with strong earthquakes (Jiang et al. 2017; Guo et al. 2018). It should be noted that three earthquakes, including the $M_{\mathrm{w}} 7.9$ Wenchuan earthquake in 2008, the $M_{\mathrm{w}} 6.6$ Lushan earthquake in 2013, and the $M_{\mathrm{w}} 5.9$ and $M_{\mathrm{w}} 5.6$ Kangding earthquake in 2014 (here taken as one seismic event), occurred in our study area. The latest studies suggested that the postseismic horizontal displacement rate caused by the Wenchuan earthquake is $\sim 1.7 \mathrm{~mm} /$ year by 9 years after this event (Wang et al. 2021), far less than the annual tectonic loading, and the postseismic effects associated with moderate-strong earthquakes are mostly concentrated near the rupture fault plane (Savage et al. 1978; Fialko 2004; Huang et al. 2014; Sun et al. 2014). So in this study, to minimize the impact of the viscoelastic relaxation effect from the Wenchuan earthquake, we divided the GNSS data into two periods, 1999-2007 and 2016-2020, corresponding to the periods before and after these three earthquakes.

The GNSS velocity solutions for the first period were collected in 1999, 2001, 2004, and 2007 from the campaign stations. The second period includes continuous and campaign stations. The campaign stations' data
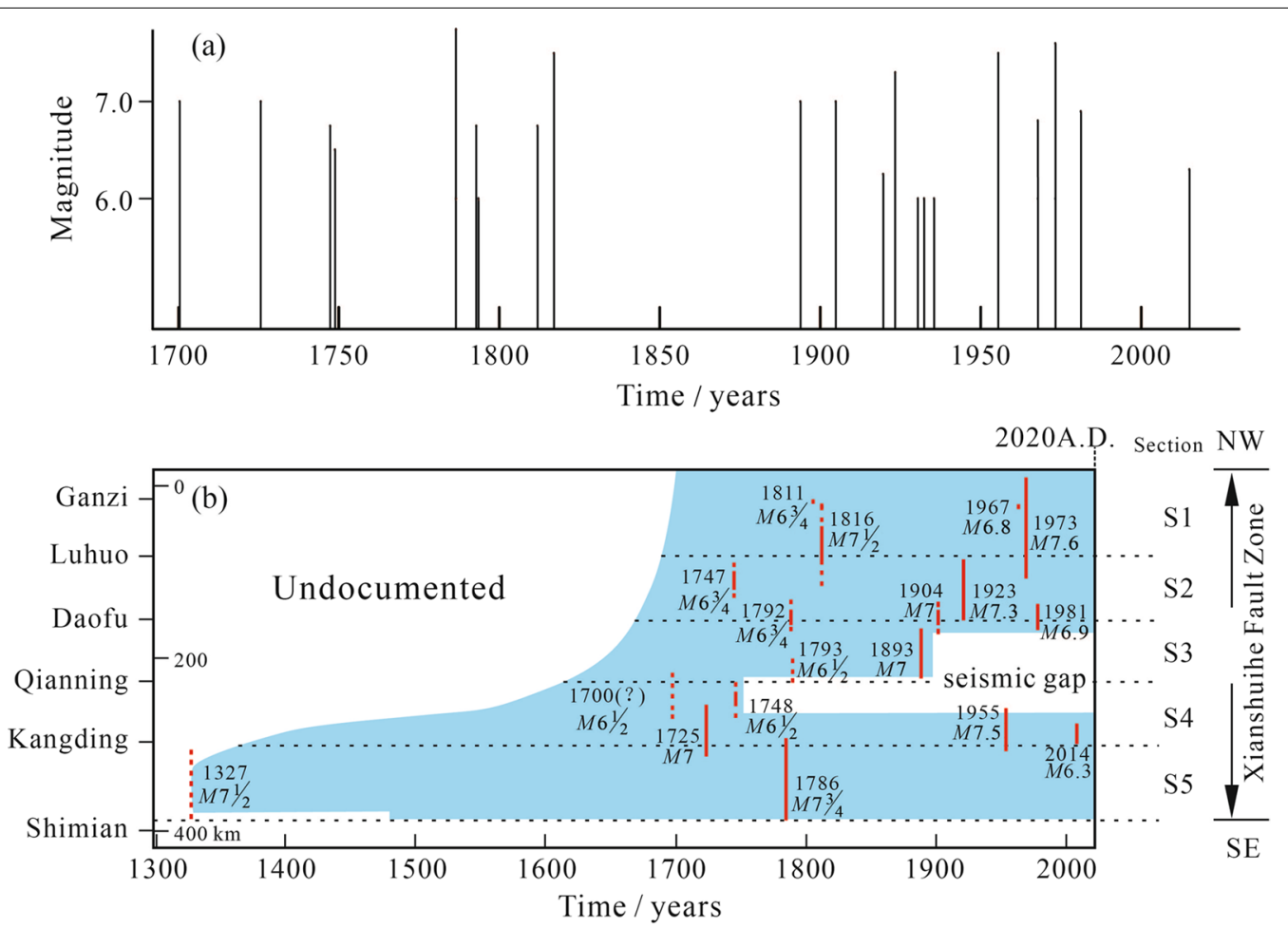

Fig. 2 Historical seismicity of the Xianshuihe Fault Zone. a $M \geq 6.0$ earthquakes in the Xianshuihe Fault Zone since 1700 . b Ruptures of $M \geq 6.0$ earthquakes in the Xianshuihe Fault Zone since 1300 ( modified from Wen et al. (2008)). Reliability of rupture determination: the vertical red solid line $>$ the vertical red dotted lines at both ends $>$ the red dotted line 


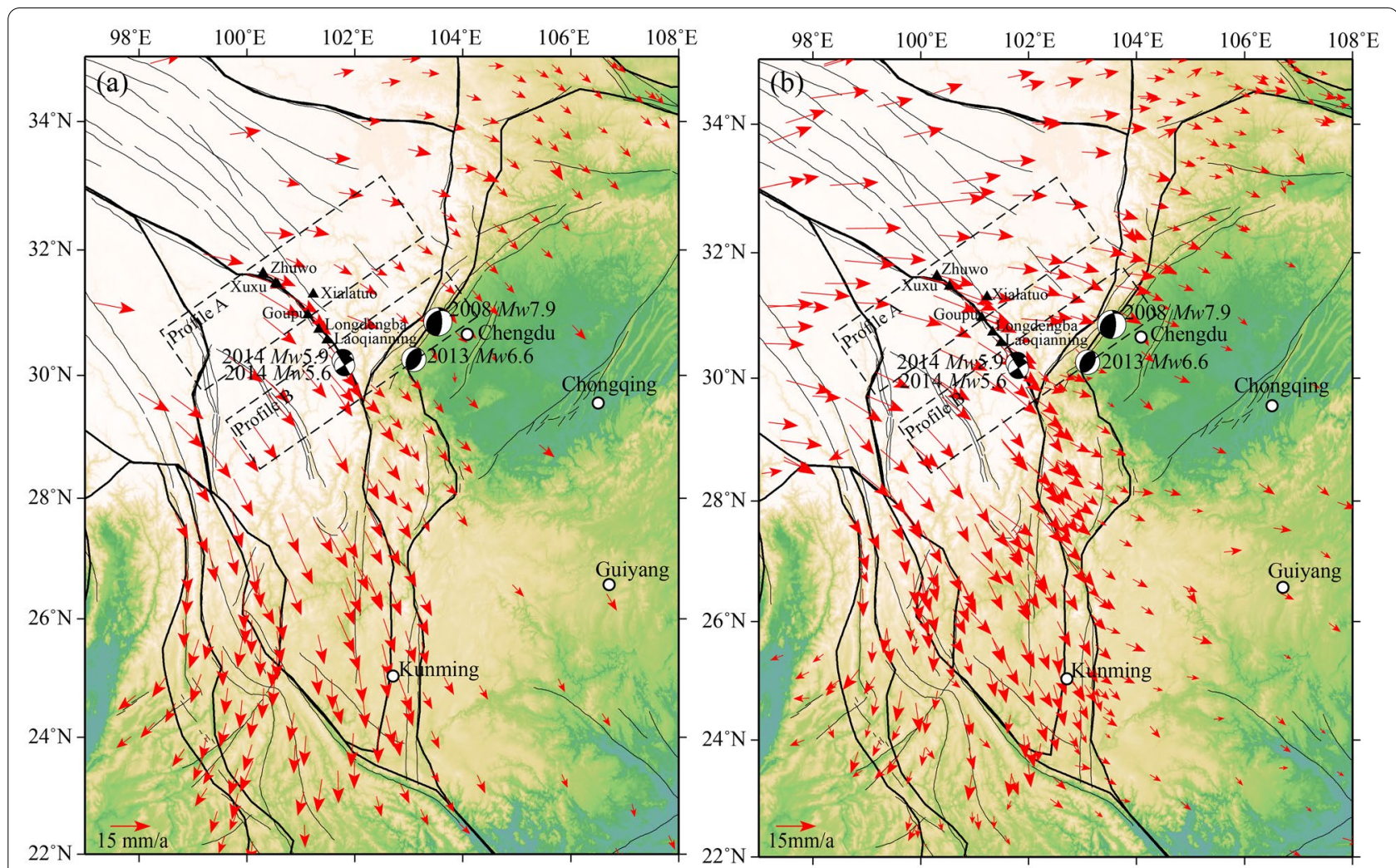

Fig. 3 GNSS velocity fields and profiles across the Xianshuihe Fault Zone. a and b The 1999-2007 and 2016-2020 GNSS velocities relative to the stable Eurasian Plate. The black triangles represent the fault-crossing observation sites. The black polygons denote the profiles plotted in Fig. 6

were collected in 2016, 2017, 2018, 2019, and 2020.We processed the GNSS data using GAMIT/GLOBK (version 10.61) (Herring et al. 2015a, b). The process mainly included three steps. (1) We processed the original observation data using GAMIT to obtain the loosely constrained daily solutions and satellite orbits. (2) Then, we performed the joint adjustment of the loosely constrained daily solutions of all the stations to obtain their position time series and estimations of the velocities in ITRF2014 using the software GLOBK10.61. For the details of the method used, refer to Liang et al. $(2018,2021)$ and Su and Zhan (2021). (3) We transformed the velocity solutions into a fixed-Eurasian reference frame (Fig. 3) using the Euler vector for Eurasia with respect to the International Terrestrial Reference System (Altamimi et al. 2017).

\section{Methods and model}

\section{Strain rate calculations}

The strain rate field is an important indicator for describing regional deformation. It is not affected by the reference frame and can reflect the crustal deformation characteristics on different spatial scales (Ward 1994; Reddy et al. 2000; Jin and Park 2006; Zhang and Sagiya 2017; Wang et al. 2019). Considering the observation errors of the actual observation data, we used the least-squares collocation method (Wu et al. 2009, 2011) to derive the strain rate fields, which has relatively good robustness. In this method, the functional relationship between the GNSS velocity and the station locations is constructed, and then, the partial derivative function of the displacement and strain are used to directly obtain the strain rate tensors $\varepsilon_{\lambda}, \varepsilon_{\phi}$, and $\varepsilon_{\lambda \phi}$ of any grid point from formula (1). In the equations, $\varphi$ is latitude; $\lambda$ is longitude; $R$ is the average radius of the earth; $u_{\varphi}$ and $u_{\lambda}$ are the velocities in the latitudinal and longitudinal directions, respectively. The details of the calculation process have been described by Wu et al. (2011):

$$
\left\{\begin{array}{l}
\varepsilon_{\varphi}=\frac{1}{R} \frac{\partial u_{\varphi}}{\partial \varphi} \\
\varepsilon_{\lambda}=\frac{1}{R \cos \varphi} \frac{\partial u_{\lambda}}{\partial \lambda}-\frac{u_{\varphi}}{R} \tan \varphi \\
\varepsilon_{\lambda \varphi}=\frac{1}{2}\left[\frac{1}{R \cos \varphi} \frac{\partial u_{\varphi}}{\partial \lambda}+\frac{u_{\lambda}}{R} \tan \varphi+\frac{1}{R} \frac{\partial u_{\lambda}}{\partial \varphi}\right]
\end{array} .\right.
$$

Then, using Eq. (2), additional strain rate vectors can be calculated: 


$$
\begin{aligned}
& \varepsilon_{1,2}=\frac{1}{2}\left(\varepsilon_{\lambda}+\varepsilon_{\phi}\right) \pm \frac{1}{2}\left(4 \varepsilon_{\lambda \phi}^{2}+\left(\varepsilon_{\lambda}-\varepsilon_{\phi}\right)^{2}\right)^{\frac{1}{2}} \\
& \gamma_{\max }=\frac{1}{2}\left(\varepsilon_{1}-\varepsilon_{2}\right) \quad \varepsilon_{\text {surface }}=\varepsilon_{\lambda}+\varepsilon_{\phi},
\end{aligned}
$$

where $\varepsilon_{1}$ is the principal tensional strain rate, $\varepsilon_{2}$ is the principal compressive strain rate, $\gamma_{\max }$ is the maximum shear strain rate, and $\varepsilon_{\text {surface }}$ is the dilatation rate.

\section{GNSS profiles and fault slip rates}

The GNSS profile can be used to reveal the differential movements and the relationship between the displacement distribution and faults, and it is widely used in the analysis of fault deformation characteristics (Jiang et al. 2009; Maurin et al. 2010; Zhang 2008). First, we selected the GNSS stations within a certain range on both sides of the fault zone. Then, we directly projected the GNSS velocities onto the directions perpendicular and parallel to the fault, and thus, the velocity component was obtained. In addition, we used an elastic dislocation model (Savage and Burford 1973) to estimate the longterm slip rate.

\section{DEFNODE negative dislocation inversion}

We used the elastic block model (McCaffrey et al. 2002). This modeling was implemented using the DEFNODE program, and it has mostly been used to estimate fault slip deficit. The model combines block rotation, uniform block strain, and Okada dislocations (Eq. 3), and it can simultaneously estimate the Block's Euler poles, the fault slip rate, and the fault-locking coefficient to provide the best fit of the geodetic, geologic, and seismic data. In this approach, the spatial variability of the fault coupling is defined by the parameter Phi (the coupling coefficient). If Phi $=0$, the fault is fully creeping or decoupled for a longterm slip rate. If Phi $=1$, the fault is completely locked. A value of Phi between 0 and 1 indicates that the fault is partially locked. The slip-rate deficit on the fault plane was derived by multiplying the fault slip vector by Phi, which provides the elastic deformation around the fault:

$$
\bar{V}_{\mathrm{sf}}=\bar{V}_{\mathrm{br}}+\bar{V}_{\mathrm{is}}+\bar{V}_{\mathrm{fs}},
$$

where $\bar{V}_{\text {sf }}$ is the observed surface velocity, $\bar{V}_{\text {br }}$ is the velocity caused by the rotation of the block, $\bar{V}_{\text {is }}$ is the velocity caused by the internal strain of the block, and $\bar{V}_{\mathrm{fs}}$ is the velocity caused by the negative dislocation of the fault locking.

Compared with general inversion programs of the same type, the DEFNODE program increases the inversion of the permanent strain inside the block, and the permanent strain inside the block can replace the partial postseismic viscoelastic relaxation effect. This program can be used for related inversions after the earthquake (Zhao et al. 2018).

\section{Inversion model}

The study area is divided into three tectonic blocks: the Bayan Har Block, the Sichuan-Yunnan Block, and the South China Block (Zhang et al. 2003). The Xianshuihe Fault Zone, the Longmenshan Fault Zone, and the Anninghe-Xiaojiang fault system were included in our inversion. The block properties (rigid body or elasticity) need to be set before the inversion. Based on previous studies (Zhao et al. 2015), we defined the Sichuan-Yunnan and Bayan Har Blocks as elastic during the inversion, which means that the locking degree (locking coefficient), the Euler vector of the block motion, and the uniform strain tensor inside the block are inverted simultaneously. The interior of the South China Block is relatively stable with weak deformation, and thus, it was modeled as rigid and the components of the strain rate were not calculated in the inversion.

Eleven nodes were set along the fault's strike, and the average distance between these nodes was approximately $35-40 \mathrm{~km}$. The depth of the fault model was set to $20 \mathrm{~km}$ based on the results of the following previous studies. Zhu et al. (2005) relocated the small earthquakes that occurred in western Sichuan and found that $90 \%$ of the small earthquake events in the Xianshuihe Fault Zone occurred in the upper crust at depths of 0-15 km. Liu et al. (2014) concluded that the stress concentration was generally within $20 \mathrm{~km}$ of the upper crust based on the joint inversion of $\mathrm{P}$-wave receiver functions and background noise. The details of the models structure are shown in Fig. 4.

\section{Results}

Strain rate fields

Since the differences in the station spacing during 19992007 and 2016-2020 would have a certain effect on the strain rate fields, we selected the data for the same GNSS station in both periods and used the least-squares collocation method to calculate the dynamic strain rate fields, which covered the Xianshuihe Fault Zone. The calculation results are shown in Fig. 5.

The strain rate fields show that (Fig. 5a) before the Wenchuan earthquake, the maximum shear strain rate was relatively high in the Luhuo and Daofu sections in the northwestern segment of the Xianshuihe Fault Zone, with maximum values of $6.0 \times 10^{-8} / \mathrm{a}$ and $5.7 \times 10^{-8} / \mathrm{a}$, respectively, which was significantly higher than that of the southeastern section (Table 2). However, after the Wenchuan and Lushan earthquakes, the maximum shear strain rates of the Luhuo and Daofu sections decreased significantly (Fig. 5b), while that of the southeastern 


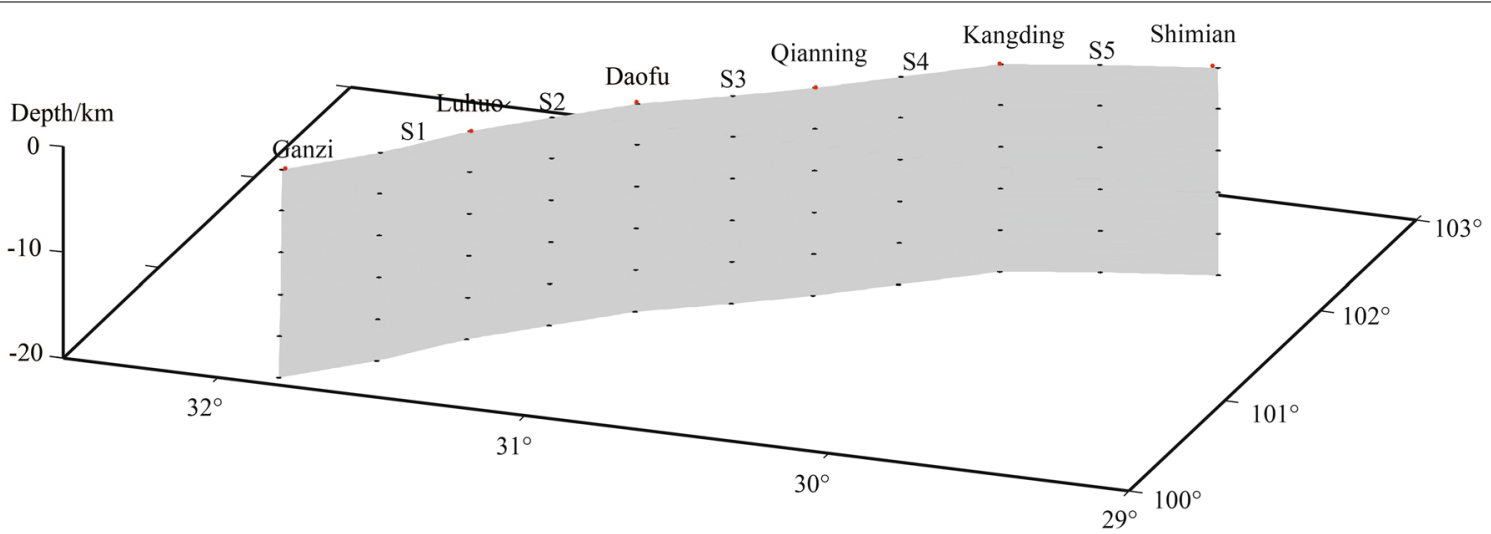

Fig. 4 Three-dimensional fault structure and node setting of the Xianshuihe Fault Zone
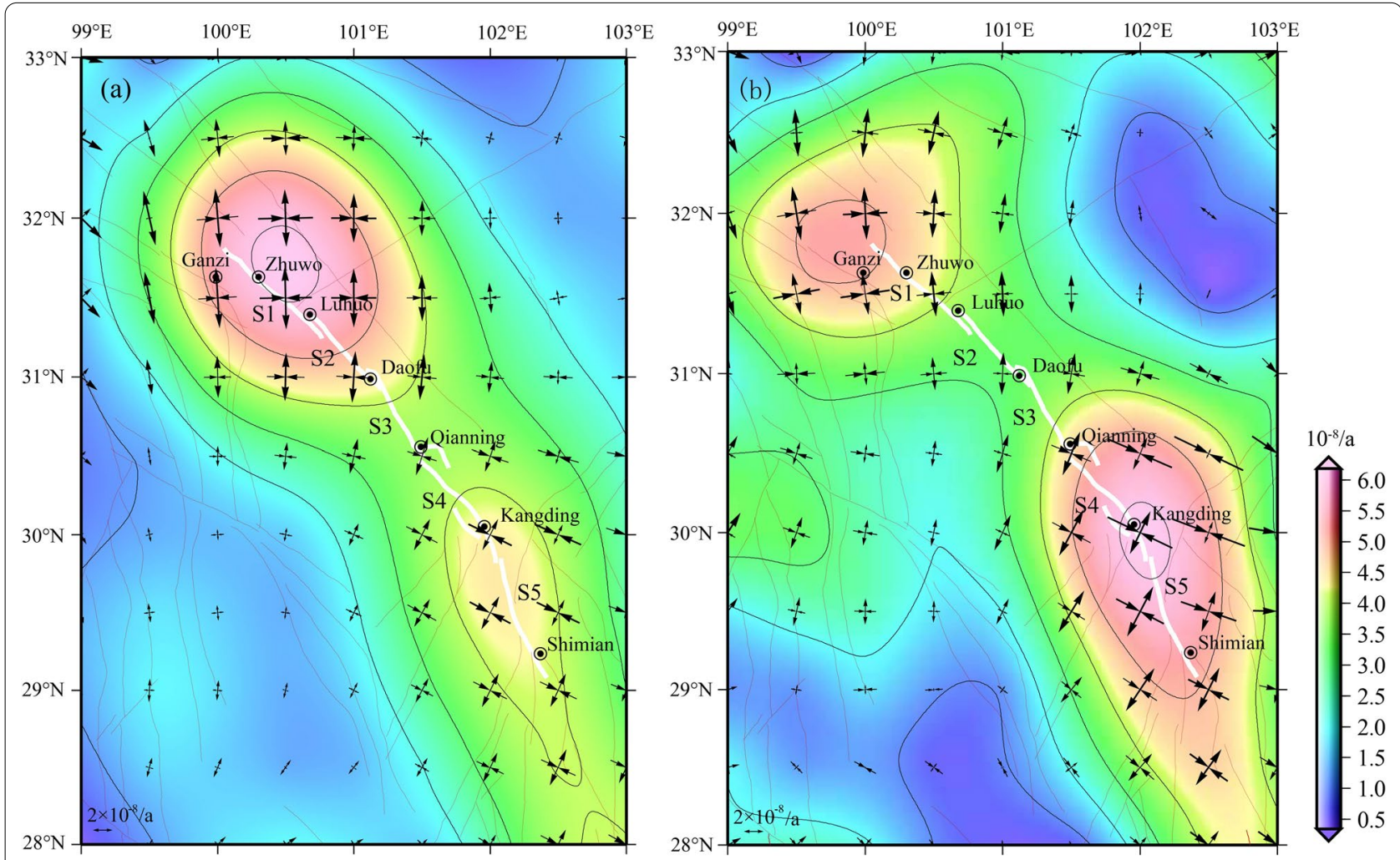

Fig. 5 Principal and maximum shear strain rate fields around the Xianshuihe Fault Zone. a and b The results during 1999-2007 and 2016-2020. The black arrows represent the principal strain rates; and the background contours represent the maximum shear strain rate

segment (Kangding and Moxi sections) increased, that is, the maximum shear strain accumulation rate increased from $4.5 \times 10^{-8} / \mathrm{a}$ to $6.2 \times 10^{-8} / \mathrm{a}$ (Table 2 ), reflecting the shear deformation pattern of the Xianshuihe Fault Zone underwent a dynamic adjustment after the Wenchuan and Lushan earthquakes. In addition, the Qianning section also deserves special attention, because the shear strain accumulation rate of this section remained unchanged during the two periods, indicating that this section tends to be locked.

The principal strain rates calculated for 1999-2007 and 2016-2020 (Fig. 5) demonstrate that the roughly E-W directed compression and $\mathrm{N}-\mathrm{S}$ directed extension were dominant in the northwestern segment of the Xianshuihe 
Table 2 Maximum shear strain rates on each segment of the Xianshuihe Fault Zone

\begin{tabular}{|c|c|c|c|c|c|}
\hline \multirow[t]{2}{*}{ Number } & \multirow[t]{2}{*}{ Fault section } & \multicolumn{2}{|c|}{$\begin{array}{l}1999-2007\left(10^{-}\right. \\
\left.8 \cdot a^{-1}\right)\end{array}$} & \multicolumn{2}{|c|}{$\begin{array}{l}2016-2020\left(10^{-}\right. \\
\left.8 \cdot a^{-1}\right)\end{array}$} \\
\hline & & Value & Error & Value & Error \\
\hline S1 & Luhuo & 6.0 & 0.34 & 5.0 & 0.18 \\
\hline S2 & Daofu & 5.7 & 0.29 & 3.2 & 0.20 \\
\hline S3 & Qianning & 3.4 & 0.34 & 3.2 & 0.19 \\
\hline S4 & Kangding & 4.5 & 0.33 & 6.2 & 0.21 \\
\hline S5 & Moxi & 4.5 & 0.39 & 6.2 & 0.20 \\
\hline
\end{tabular}

Fault, and from NW to SE along the strike of the Xianshuihe Fault, the compression gradually transitioned to NW-SE directed and the extension transitioned to NE-SW directed. Furthermore, we noted that the values of the principal strain rates in the northwestern segment were larger than those in the southeastern segment during 1999-2007. However, after the Wenchuan and Lushan earthquakes, the values of the principal strain rate in the northwestern segment decreased, while the values in the southeastern segment significantly increased, indicating that the tectonic stress on the southeastern section enhanced.

\section{GNSS velocity profile}

We created two velocity profiles (A and B) across the Xianshuihe Fault Zone. The locations of profiles are shown in Fig. 3. The profiles are $400 \mathrm{~km}$ long and $130 \mathrm{~km}$ (A) and $110 \mathrm{~km}$ (B) wide.

The velocity profile results in Fig. 6 show that an obvious left-lateral strike deformation characteristic dominates in the Xianshuihe Fault Zone. Before the $M_{\mathrm{w}} 7.9$ Wenchuan earthquake, the left-lateral strike-slip rate of the northwestern segment of the Xianshuihe Fault Zone was $\sim 11.5 \mathrm{~mm} / \mathrm{a}$, but it decreased to $\sim 7.8 \mathrm{~mm} / \mathrm{a}$ after the Wenchuan and Lushan earthquakes. Moreover, the nearfield deformation width of the fault was about $125 \mathrm{~km}$ before the Wenchuan earthquake, but it decreased to within the vicinity of the fault $(\sim 50 \mathrm{~km})$ after the earthquake.

The velocity profile results (Fig. 6c, 6d) show that before the $M_{\mathrm{w}} 7.9$ Wenchuan earthquake, the left-lateral strike-slip rate of the southeastern segment of the Xianshuihe Fault Zone was $\sim 11 \mathrm{~mm} / \mathrm{a}$, but it hardly decreased after the $M_{\mathrm{w}} 6.6$ Lushan and $M_{\mathrm{w}} 5.9$ Kangding earthquakes, kept a left-lateral strike-slip rate of $\sim 10.8 \mathrm{~mm} / \mathrm{a}$. Moreover, the near-field deformation width of the fault almost unchanged during the two periods.

\section{Fault locking}

Based on the fault model above, we obtained the optimal model parameters through multiple calculations. Figure 7 shows the GNSS velocity residuals for the two time periods for the best-fit model. The predicted velocities fit the GNSS velocities well without systematic error. The majority of the residuals are within the error range, and the directions of the residuals are stochastic throughout
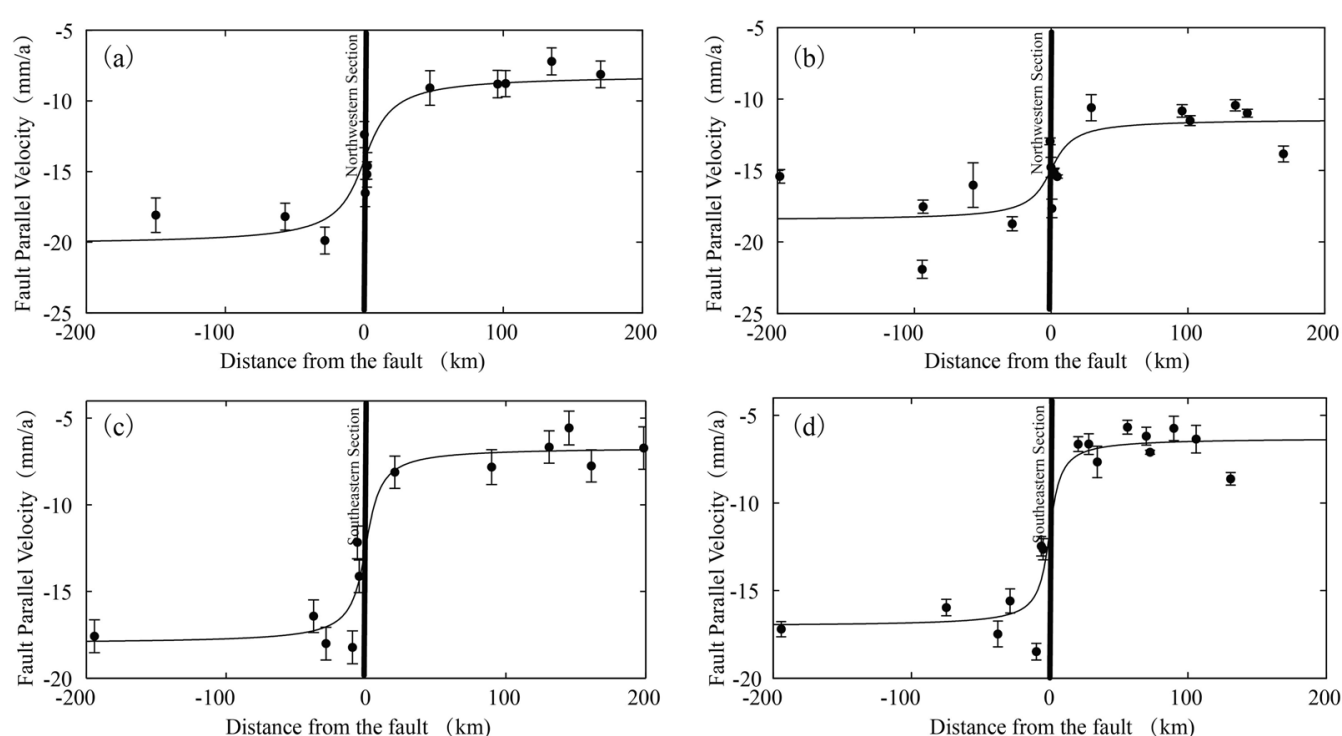

Fig. 6 GNSS velocity profiles across the Xianshuihe Fault Zone. $\mathbf{a}$ and $\mathbf{b}$ The velocity parallel to the northwestern section of the Xianshuihe Fault Zone during 1999-2007 and 2016-2020; and $\mathbf{c}$ and $\mathbf{d}$ the velocity parallel to the southeastern section of the Xianshuihe Fault Zone during 1999-2007 and 2016-2020 


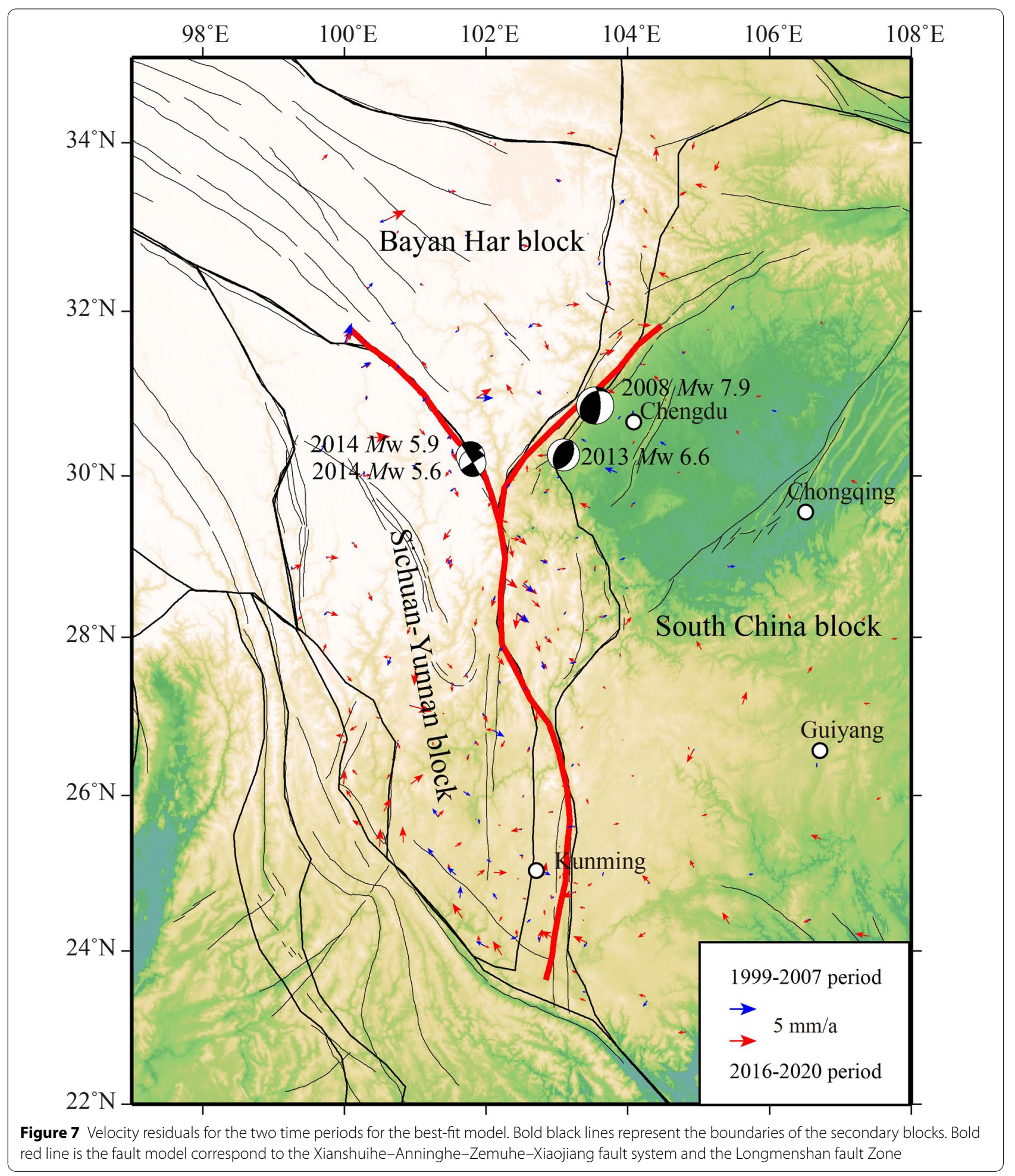

the entire study area. Only the residuals near the Zemuhe Fault Zone are slightly larger.

The inversion results show that before the Wenchuan earthquake (Fig. 8a), the Luhuo section of the Xianshuihe
Fault Zone was strong coupled at depth of $\sim 5 \mathrm{~km}$, with an average fault-coupling coefficient of 0.85 , except the location of Ganzi locked to a depths of $\sim 16 \mathrm{~km}$ which may be affected by boundary effects. The Daofu section was 

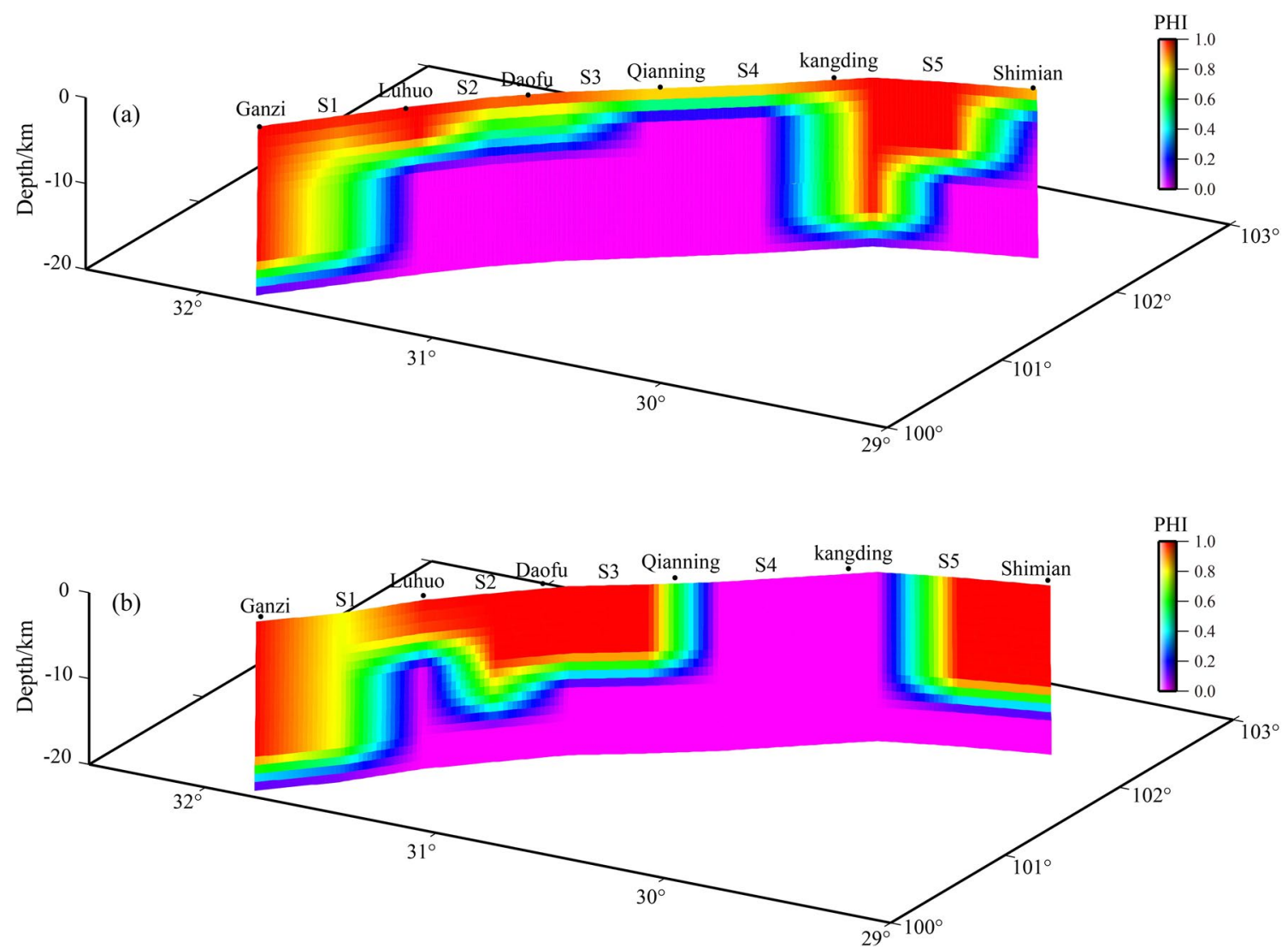

Fig. 8 Locking degree in the Xianshuihe Fault Zone. a and b The locking degrees of the Xianshuihe Fault Zone in 1999-2007 and 2016-2020. S1-S5 represent the Luhuo, Daofu, Qianning, Kangding, and Moxi sections, respectively

shallowly coupled at depths of $<5 \mathrm{~km}$ and the Qianning section was coupled only at the surface. Moreover, the Kangding section also showed a shallow locking depth at the surface. However, the Moxi section exhibited a high degree of locking, which was locked to a depth of $\sim 16 \mathrm{~km}$, and the locking depth in the southeastern segment gradually weakened from northwest to southeast. After the Wenchuan and Lushan earthquakes (Fig. 8b), the locking degree of the Kangding section became completely decoupled and freely crept. In contrast, the locking degrees of the Daofu, Qianning, and Moxi sections increased, with average coupling coefficients of greater than 0.9 at depths $8 \mathrm{~km}, 8 \mathrm{~km}$ and $16 \mathrm{~km}$, respectively. The details are shown in Fig. 8b.

The fault-parallel slip-rate deficit demonstrates that the Xianshuihe Fault Zone experienced a left-lateral slip-rate deficit (positive value) (Fig. 9). Before the Wenchuan earthquake, the left-lateral slip-rate deficit of the Luhuo and Daofu sections was the highest $(8-10 \mathrm{~mm} / \mathrm{a})$, followed by the Moxi Sect. (6-8 mm/a). After the Wenchuan and Lushan earthquakes, the left-lateral slip-rate deficit decreased to $2-6 \mathrm{~mm} / \mathrm{a}$ in the Luhuo, Daofu, and Qianning sections. After the Wenchuan and Lushan earthquakes, the Kangding section exhibited almost no left-lateral slip-rate deficit, and that of the southern tip of the Moxi section remained at approximately $6-8 \mathrm{~mm} / \mathrm{a}$.

\section{Discussion}

Different impacts of major earthquakes on the Xianshuihe Fault Zone

The spatial pattern and rate of the strain accumulation during the interseismic phase are very important for interpreting the mechanisms of earthquakes and for evaluating the seismic potentials of faults (Navarro et al. 2003; Fialko, 2006; Moreno et al. 2010). The current deformation characteristics of the Xianshuihe Fault Zone can be described by the strain rate field, the fault slip across the block boundaries, and the fault coupling based on geodetic data. Our results show that the high shear strain rates were concentrated in the Xianshuihe Fault Zone, and the values in the northwestern section were significantly larger than those in the southeastern section before the Wenchuan earthquake, which is consistent with the previous studies (Xu et al. 2018; Li et al. 2019). The higher shear strain rate along the Xianshuihe Fault 

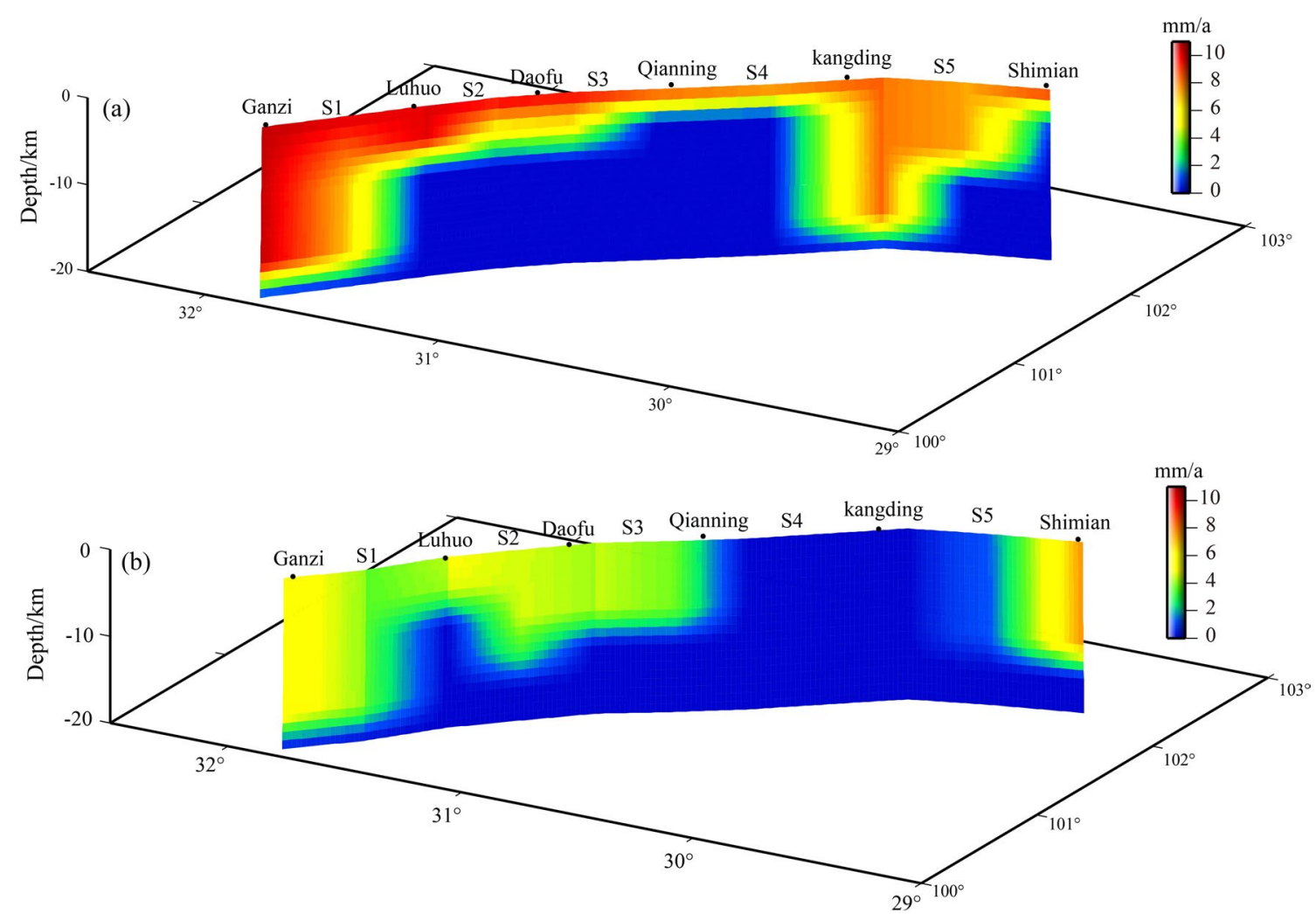

Fig. 9 Fault-parallel slip-rate deficit in the Xianshuihe Fault Zone. a and b The fault-parallel slip-rate deficits in 1999-2007 and 2016-2020. S1-S5 represent the Luhuo, Daofu, Qianning, Kangding, and Moxi sections, respectively

Zone is consistent with its high slip rate (Meade, 2007; Qu et al. 2018; Zhang et al. 2019), which is a basic feature of the block-like tectonic extrusion model (Avouac and Tapponnier, 1993; Tapponnier et al. 1982).

After the strong Wenchuan and Lushan earthquakes, the shear strain rate in the Luhuo and Daofu sections significantly decreased. The left-lateral slip-rate and the sliprate deficit in these sections also decreased (Figs. 6b, 9b). We conclude that these variations were mainly caused by the large-scale decoupling of the central and southern sections of the Longmenshan Fault Zone accompanied by the Wenchuan and Lushan earthquakes. After the Wenchuan earthquake, the extrusion rate of the Bayan Har Block toward the Sichuan Basin accelerated which decreased the far-field left-lateral strike-slip rate and the fault slip-rate deficit and increased the tensile movement of the northwestern section of the Xianshuihe Fault. These major earthquakes may have alleviated the strain accumulation rate in the northwestern segment of the Xianshuihe Fault Zone.

To further verify the impacts of the Wenchuan earthquake and the other regional strong earthquakes on the Xianshuihe Fault Zone; we also collected near-field cross-fault short-baseline observational data for the northwestern segment of the Xianshuihe Fault Zone from 1980 to 2019. The distributions of the fault-crossing sites are shown in Fig. 3. Fault-crossing deformation observations can directly reflect the local tectonic deformation and changes in the stress state of active faults, and they have been used to analyze near-field fault activity (Bo et al. 1998; Li et al. 2016, 2017). In this study, the calculation method of Bo et al. (1998) was used to quantitatively calculate the horizontal strike-slip component and the horizontal tension and compression components. The positive slope of the curve indicates right-lateral and tension movements (Fig. 10).

The results of the fault activity analysis (Fig. 10) reveal that the northwestern segment of the Xianshuihe Fault Zone has predominantly experienced left-lateral strikeslip movement (the slope of the curve was negative), with a low tension and compression rate, before the Wenchuan earthquake. However, after the Wenchuan earthquake, and especially after the Lushan earthquake, the tensile activity in the northwestern segment of the Xianshuihe Fault Zone increased significantly. Furthermore, it was found that the near-field left-lateral strike-slip movement at some of the sites, such as Zhuwo, Goupu, and Laoqianning, decreased slightly. Therefore, the 

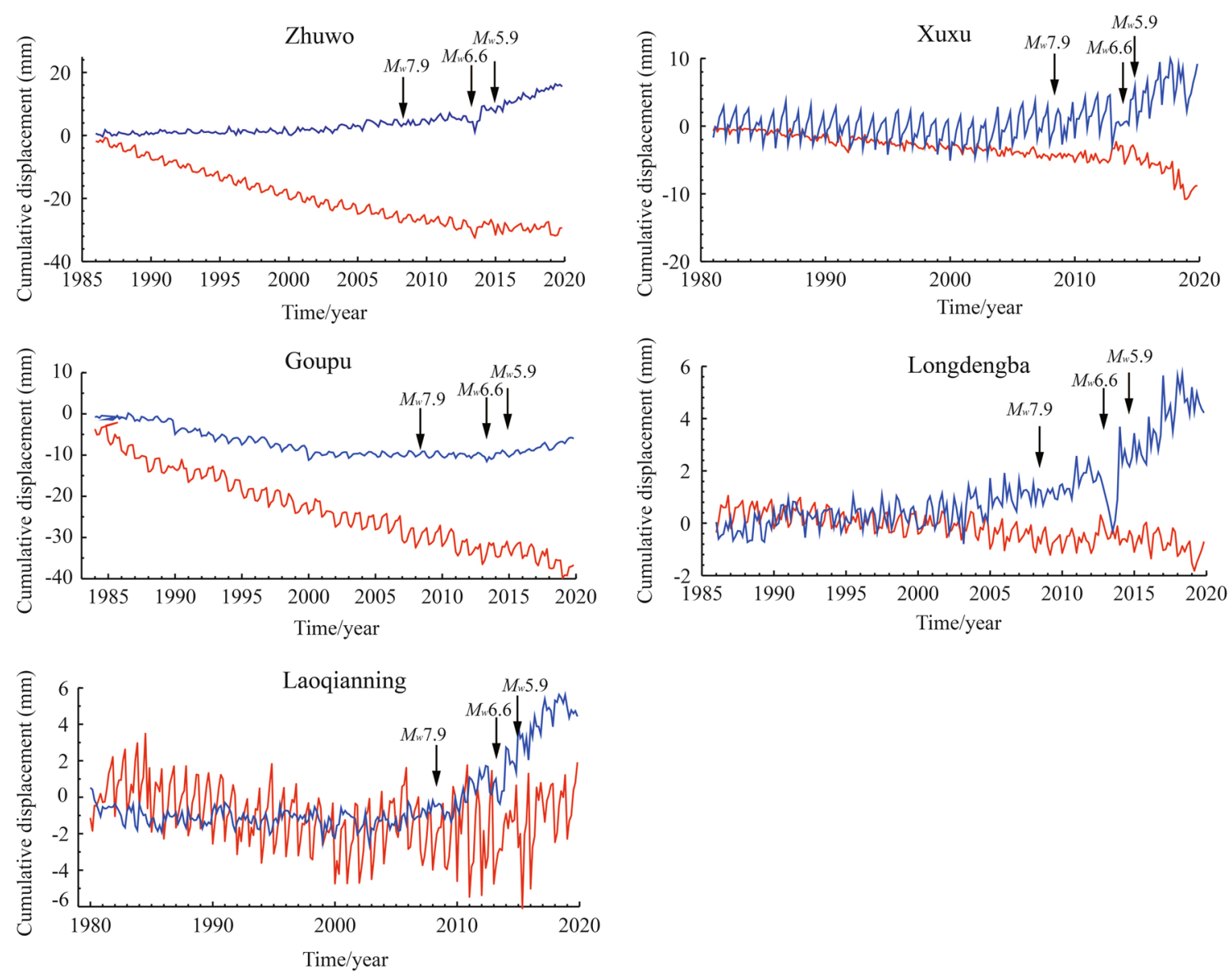

Fig. 10 Time series curves of the motion components of the Xianshuihe Fault Zone. The red line denotes the horizontal strike-slip component, and the blue line denotes the horizontal tension and compression components

results of the near-field cross-fault observations also indicate that the Wenchuan and Lushan earthquakes affected the movement features and strain accumulation rate of the northwestern section of the Xianshuihe Fault Zone.

In addition, we noted that the shear strain rates of the southeastern section of the Xianshuihe Fault increased after the series of earthquakes (Fig. 5b). The Kangding section has almost no left-lateral slip-rate deficit (Fig. 9b) and still has a high left-lateral slip-rate, while the Moxi section remains strongly coupled, with a high left-lateral slip-rate deficit of $8 \mathrm{~mm} / \mathrm{a}$ in the second period (Figs. $8 \mathrm{~b}$, 9b). This is consistent with the latest InSAR results (Qiao and Zhou 2021), which also indicate a high shallow slip rate $(16.3-19.8 \mathrm{~mm} / \mathrm{a})$ in the western Kangding section during 2014-2019, and a locking depth of $18.5 \mathrm{~km}$ in the Moxi section. The southeastern section of the Xianshuihe Fault Zone is located in the triple junction area where the three major fault zones interact and restrict one another. The Wenchuan and Lushan earthquakes occurred in the central northern segment and southern segment of the
Longmenshan Fault Zone, respectively. The postseismic geological survey and precise aftershock positioning results reveal that the ruptures of the Lushan earthquake and the Wenchuan earthquake did not pass through, and the Lushan earthquake did not cause the entire southern section of the Longmenshan fault to decouple (Fang et al. 2013; Gao et al. 2014; Xu et al. 2013). The triple junction area is still in a strong compressional strained environment. More than a year after the Lushan earthquake, the $2014 M_{\mathrm{w}} 5.9$ and $M_{\mathrm{w}} 5.6$ Kangding earthquakes occurred on the Selaha fault between the Kangding and Qianning sections of the Xianshuihe Fault Zone, which also confirms that this area had a high level of stress accumulation after the Wenchuan and Lushan earthquakes. However, owing to the small-scale rupture and the limited energy released by the $M_{\mathrm{w}} 5.9$ Kangding earthquake, the event was not sufficient to significantly change the strain throughout the entire triple junction area. Therefore, the southeastern section of the Xianshuihe Fault still had a high strain accumulation rate after the series 
of earthquakes. All of these results indicate that the surrounding strong earthquakes, i.e., the $M_{\mathrm{w}} 7.9$ Wenchuan earthquake in 2008 and the $M_{\mathrm{w}} 6.6$ Lushan earthquake in 2013, had evident differential impacts on the strain accumulation pattern of the Xianshuihe Fault Zone.

\section{Shallow creep along the Xianshuihe fault}

Previous studies have demonstrated that there is shallow aseismic slip on the Xianshuihe Fault Zone (Allen et al. 1991; Du et al. 2010; Qiao and Zhou 2021; Li and Bürgmann 2021). Allen et al. (1991) first pointed out a stable shallow creep of $6 \mathrm{~mm} / \mathrm{a}$ at the Xialatuo site near the 1973 Luhuo earthquake rapture during 1976-1984. Based on short baselines and short leveling, Du et al. (2010) estimated a fault creep rate of $10.27 \mathrm{~mm} / \mathrm{a}$ at the Xialatuo site (located on the Luhuo segment) in the first five years after the Luhuo earthquake, and showed that after 1979, the creep rate has been slowing down to $2.27 \mathrm{~mm} / \mathrm{a}$ in 2009 gradually following a logarithmic function, and the fault plane has been tending to recouple with some strain built-up. Moreover, they estimated the fault segment will entirely re-lock, enter the stage of interseismic locking in the next 15 to 25 years. Recently, Li and Bürgmann (2021) used high-resolution InSAR data to show evidence of fault creep, suggesting the Xialatuo, Goupu-Songlingkou and Bamei-SelahaKangding creep from 0-6 mm/year along the Xianshuihe Fault. In contrast, Li et al. (2021) found a shallow locking depth of $2-3 \mathrm{~km}$ of the Luhuo section, and suggested that creeping at the Xialatuo site ended during 2000-2018. Our inversion result showed that the Luhuo segment was locked down to $3-5 \mathrm{~km}$ with an average fault-coupling coefficient of 0.85 , consistent with those results by $\mathrm{Du}$ et al. (2010) and Li et al. (2021), indicating that the fault plane of the Luhuo segment is in a state of re-coupling with some strain built-up currently.

The creeping section identified by our inversion result is from Qianning Basin to the Kangding County along the Xianshuihe fault, which is in good agreement with the latest studies (Li and Bürgmann 2021; Li et al. 2021). This section in the period of 1999-2007 showed a shallow locking depth at the surface except for the location of Kangding locked to a depth of $\sim 16 \mathrm{~km}$. The $2014 M_{\mathrm{w}} 5.9$ Kangding earthquake occurred in the north of Kangding County that was relatively weakly coupled with an average coupling coefficient of 0.6 , which led to part of the strain energy releasing, and this section experienced completely decoupling and freely creeping between 2016 and 2020. An issue that deserves attention is that the $2014 M_{\mathrm{w}} 5.9$ Kangding earthquake occurred in the weakly coupled area we inverted in the 1999-2007 period, one reason we suggested which is triggered owing to stress perturbations from surrounding large earthquakes, especially the $2008 M_{\mathrm{w}} 7.9$ Wenchuan earthquake and the $2013 M_{\mathrm{w}} 6.6$ Lushan earthquake (Shan et al. 2013).

\section{Seismic hazard analysis}

The seismic gaps, locking degree, low b-value section of the background seismic activity, and Coulomb stress changes are effective indicators for determining the locations where strong earthquakes may occur in the future (Hubert-Ferrari et al. 2000; Nalbant et al. 1998; Shan et al. 2015; Stein et al. 1997; Wen et al. 2008; Yi et al. 2008).

The spatial and temporal distributions of the earthquake ruptures caused by the major earthquakes along the Xianshuihe Fault Zone reveal that no strong earthquakes have occurred in the Qianning section since the M7.0 Qianning earthquake in 1893, and the elapsed time exceeds the recurrence interval of the historic strong earthquakes, indicating that this seismic gap is a potential location for strong earthquakes in the future. Following the Wenchuan and Lushan earthquakes, the locking degree and locking depth of the Qianning section increased. In addition, the GNSS-derived strain rates show that the Qianning section is an invariant deformation adjustment zone. These results indicate that the Qianning section is in a coupled state with little deformation. Yi et al. (2008) calculated the b-value from seismic data (from the China Seismic Network and Sichuan Regional Seismic Network) for 1976-2006 and found a large-scale asperity with a low b-value from Daofu to Qianning (defined as the Qianning section here) of the Xianshuihe Fault Zone. The weak deformation of this section may be related to the large-scale asperity. In addition, the Coulomb stress change shows that the occurrences of the Wenchuan and Lushan earthquakes caused increased stress in the Qianning section (Li et al. 2012; Luo and Liu 2018; Parsons et al. 2008; Shan et al. 2013; Toda et al. 2008; Wan and Shen 2010), which is consistent with our inversion results. Therefore, we suggest that the Qianning section may be a potential seismogenic source for a future strong earthquake.

Another potential seismogenic source of a strong future earthquake is the Moxi section, which is located at the triple junction of the Xianshuihe Fault Zone, the Anninghe Fault Zone, and the Longmenshan Fault Zone. The tectonics of this area are especially complex. It has been over 200 years since the M7.7 KangdingMoxi earthquake occurred in 1786 in the Moxi section (Wen et al. 2008). Owing to the influence of long-term tectonic loading, this section already has a high strain accumulation (Wang et al. 2016). In addition, our faultcoupling inversion results show that this section has a high degree of fault-locking and a high left-lateral rate deficit. Moreover, the Coulomb stress change in this 
section has been enhanced by historical strong earthquakes (Li et al. 2020b; Shao et al. 2016). Therefore, the risk of future strong earthquakes in this area also requires more attention.

\section{Conclusions}

In this study, we focus on exploiting the dynamic deformation characteristics of the Xianshuihe Fault Zone and its potential risk of strong earthquakes occurring using GNSS data for 1999-2007 and 2016-2020. The main conclusions drawn are as follows:

(1) The Xianshuihe Fault Zone had a relatively high shear strain rate, and the values of the northwestern section were greater than those of the southeastern section before the Wenchuan earthquake, which is consistent with the spatial differences in the slip rate.

(2) The deformation mode of the Xianshuihe Fault Zone underwent a dynamic adjustment after the Wenchuan and Lushan earthquakes. The shear strain accumulation rates of the Luhuo and Daofu sections decreased from $6.0 \times 10^{-8} / \mathrm{a}$ to $3.2 \times 10^{-8} / \mathrm{a}$, while that of the southeastern segment increased from $4.5 \times 10^{-8} / \mathrm{a}$ to $6.2 \times 10^{-8} / \mathrm{a}$. The slip rate and deformation width of the Xianshuihe Fault Zone also changed during these two periods, reflecting the differential impacts of the surrounding major earthquakes on the deformation pattern of the Xianshuihe Fault Zone.

(3) The locking degree of the Qianning and Moxi sections increased significantly after the Wenchuan earthquakes, while no slip-rate deficit occurred in the Kangding section, which is at present in a state of creeping from the surface to a depth of $20 \mathrm{~km}$. Strain accumulation characteristics and the recent rupture history of the Xianshuihe Fault Zone suggest that both the Qianning and Moxi sections have a high potential for future strong earthquakes.

\footnotetext{
Abbreviations

GNSS: Global Navigation Satellite System; InSAR: Interferometric Synthetic Aperture Radar; CMONOC I: Crustal Movement Observation Network of China; CMONOC II:Tectonic and Environmental Observation Network of Mainland China.

\section{Acknowledgements}

We acknowledge the CMONOC I (Crustal Movement Observation Network of China) and CMONOC II (Tectonic and Environmental Observation Network of Mainland China) for providing GNSS observations. We would like to thank LetPub (www.letpub.com) for its linguistic assistance during the preparation of this manuscript. Most figures were plotted using the Generic Mapping Tools (Wessel et al. 2013).
}

\section{Authors' contributions}

$L L, Y W$, and $Y L$ designed the research, analyzed the results and wrote the manuscript. WZ and XL performed the GNSS data processing and participated in the creation of the graphics. All authors have read and agreed to the published version of the manuscript.

\section{Funding}

This study was supported by the National Natural Science Foundation of China (Nos. 41974011, 41874116), the Science for Earthquake Resilience Program (No. XH18067Y), and the National Key Research and Development Program of China (No. 2018YFC1503606).

\section{Availability of data and materials}

The horizontal GNSS velocity data used in this study can be accessed at ftp:// 60.30.77.19.

\section{Declarations}

\section{Competing interests}

This manuscript has not been published or presented elsewhere in part or in entirety and is not under consideration by another journal. We have read and understood your journal's policies, and we believe that neither the manuscript nor the study violates any of them. There are no conflicts of interest to declare.

\section{Author details}

${ }^{1}$ The First Monitoring and Application Center, CEA, Tianjin 300180, China. ${ }^{2}$ National Institute of Natural Hazards, Ministry of Emergency Management of China, Beijing 100085, China.

Received: 6 August 2021 Accepted: 3 February 2022

Published: 22 February 2022

\section{References}

Ader T, Avouac JP, Liu-Zeng J, Lyon-Caen H, Bollinger L, Galetzka J, Genrich J, Thomas M, Chanard K, Sapkota SN (2012) Convergence rate across the Nepal Himalaya and interseismic coupling on the Main Himalayan Thrust: Implications for seismic hazard. J Geophys Res Solid Earth 117(B4):B04403. https://doi.org/10.1029/2011JB009071

Allen CR, Luo ZL, Qian H, Wen XZ, Zhou HW, Huang WS (1991) Field study of a highly active fault zone: The Xianshuihe fault of southwestern China. Geol Soc Am Bull 103(9):1178-1199. https://doi.org/10.1130/0016-7606(1991)103

Altamimi Z, Métivier L, Rebischung P, Rouby H, Collilieux X (2017) ITRF2014 plate motion model. Geophys J Int 209:1906-1912. https://doi.org/10. 1093/gji/ggx136

Avouac JP, Tapponnier P (1993) Kinematic model of active deformation in central Asia. Geophys Res Lett 20(10):895-898. https://doi.org/10.1029/ 93GL00128

Bai M, Chevalier ML, Pan J, Replumaz A, Leloup PH, Métois M, Li H (2018) Southeastward increase of the late Quaternary slip-rate of the Xianshuihe fault, eastern Tibet. Geodynamic and seismic hazard implications. Earth Planet Sci Lett 485:19-31. https://doi.org/10.1016/j.epsl.2017.12.045

Bo W, Xie J, Guo L (1998) Analysis and exploration of deformation of Babaoshan fault belt. Earthquake 18(1):63-68 (CNKI:SUN:D IZN.0.1998-01-009)

Deng QD, Cheng SP, Ma J, Du P (2015) Seismic activities and earthquake potential in the Tibetan Plateau. Chin J Geophys 57(5):678-697. https:// doi.org/10.6038/cjg20140701

Dogru A, Gorgun E, Aktug B, Ozener H (2018) Seismic hazard assessment of the central North Anatolian Fault (Turkey) from GPS-derived strain rates and b-values. Geomat Nat Haz Risk 9:356-367. https://doi.org/10.1080/ 19475705.2018.1441193

Du F, Wen XZ, Zhang PZ (2010) Post-seismic slip and deformation on the Luhuo segment of the Xianshuihe fault zone. Acta Geophysica Sinica 53(10):2355-2366. https://doi.org/10.3969/j.issn.0001-5733.2010.10.009

Fang LH, Wu JP, Wang WL, Lv ZY, Wang CZ, Yang T, Cai Y (2013) Relocation of mainshock and aftershock sequences of Ms7.0 Sichuan Lushan earthquake. Chin Sci Bull 58:1901-1909. https://doi.org/10.1007/ s1 1434-013-6000-2 
Fialko Y (2006) Interseismic strain accumulation and the earthquake potentia on the southern San Andreas fault system. Nature 441:968-971. https:// doi.org/10.1038/nature04797

Fialko Y (2004) Evidence of fluid-filled upper crust from observations of postseismic deformation due to the 1992 Mw7.3 Landers earthquake. J Geophys Res Solid Earth 109: B08401. https://doi.org/10.1029/2004j b002985

Gan W, Zhang P, Shen ZK, Niu Z, Wang M, Wan Y, Zhou D, Cheng J (2007) Present-day crustal motion within the Tibetan Plateau inferred from GPS measurements. J Geophys Res Solid Earth. https://doi.org/10.1029/2005J B004120

Gao Y, Wang Q, Zhao B, Shi Y (2014) A rupture blank zone in middle south part of Longmenshan Faults: Effect after Lushan Ms7.0 earthquake of 20 April 2013 in Sichuan. China Sci China (earth Sci) 57:2036-2044. https://doi. org/10.1007/s11430-014-4827-2

Guo RM, Zheng Y, Tian W, Xu JQ, Zhang WT (2018) Locking status and earthquake potential hazard along the Middle-South Xianshuihe Fault. Remote Sens 10(12):2048. https://doi.org/10.3390/rs10122048

Herring T A, King RW, Floyd MA (2015a) GAMIT Reference Manual. GPS Analysis at MIT(Release 10.6), Department of Earth, Atmosphere, and Planetary Sciences Massachusetts Institute Technology. http://geoweb.mit.edu/gg/

Herring T A, Floyd M A, King R W (2015b) GLOBK Reference Manual. Global Kalman filter VLBI and GPS analysis program (Release 10.6), Department of Earth, Atmosphere, and Planetary Sciences Massachusetts Institute Technology. http://geoweb.mit.edu/gg/

Huang MH, Bürgmann R, Freed AM (2014) Probing the lithospheric rheology across the eastern margin of the Tibetan Plateau. Earth Planet Sci Lett 96:88-96. https://doi.org/10.1016/j.epsl.2014.04.003

Hubert-Ferrari A, Barka A, Jacques E, Nalbant SS, Meyer B, Armijo R, Tapponnier P, King GC (2000) Seismic hazard in the Marmara Sea region following the 17 August 1999 Izmit earthquake. Nature 404:269-273. https://doi.org/ $10.1038 / 35005054$

Ji L, Zhang W, Liu C, Zhu L, Xu J, Xu X (2020) Characterizing interseismic deformation of the Xianshuihe fault, eastern Tibetan Plateau, using Sentinel-1 SAR images. Adv Space Res 66:378-394. https://doi.org/10.1016/j.asr.2020.03.043

Jiang G, Xu X, Chen G, Liu Y, Fukahata Y, Wang H, Yu G, Tan X, Xu C (2015) Geodetic imaging of potential seismogenic asperities on the XianshuiheAnninghe-Zemuhe fault system, southwest China, with a new 3-D viscoelastic interseismic coupling model. J Geophys Res 120(3):1855-1873. https://doi.org/10.1002/2014jb011492

Jiang Z, Yuan L, Huang D, Yang Z, Chen W (2017) Postseismic deformation associated with the 2008 Mw7.9 Wenchuan earthquake, China: Constraining fault geometry and investigating a detailed spatial distribution of afterslip. J Geodyn 112:12-21. https://doi.org/10.1016/j.jog.2017.09.001

Jiang ZS, Fang Y, Wu YQ, Wang M, Du F, Ping JJ (2009) The dynamic process of regional crustal movement and deformation before Wenchuan Ms8.0 earthquake. Chin J Geophys 52(2):505-518. doi:CNKI:SUN:D QWX.0.2009-02-023

Jin S, Park PH (2006) Strain accumulation in South Korea inferred from GPS measurements. Earth Planets Space 58(5):529-534. https://doi.org/10. 1186/BF03351950

King GC, Stein RS, Lin J (1994) Static stress changes and the triggering of earthquakes. Bull Seismol Soc Am 84:935-953. https://doi.org/10.1029/ 94JB00611

Li Y, Chen L, Lu Y (2012) Numerical simulation on the influences of Wenchuan earthquake on the surrounding faults. Earthquake Sci 25(2):143-150. https://doi.org/10.1007/s11589-012-0841-7

Li Y, Chen L, Liu S, Zhan W (2017) Discussion on mechanism of cross-fault baseline variations along the northwestern segment of the Xianshuihe fault zone. Chin J Geophys 60(2):554-563. https://doi.org/10.6038/cjg20 170210

Li Y, Liu M, Li Y, Chen L (2019) Active crustal deformation in southeastern Tibetan Plateau: The kinematics and dynamics. Earth Planet Sci Lett 523:115708. https://doi.org/10.1016/j.epsl.2019.07.010

Li J, Zhou B, Li T, Yang Y, Li Z (2020a) Locking depth, slip rate, and seismicity distribution along the Daofu-Kangding segment of the Xianshuihe fault system, eastern Tibetan Plateau. J Asian Earth Sci 193:104328. https://doi. org/10.1016/j.jseaes.2020.104328

Li YJ, Shi FQ, Zhang H, Wei WX, Xu J, Shao ZG (2020b) Coulomb stress change on active faults in Sichuan-Yunnan region and its implications for seismic hazard. Seismol Geol 42(2):526-546. https://doi.org/10.3969/j.issn.02534967.2020.02.017

Li Y, Nocquet J-M, Shan X, Jian H (2022) Heterogeneous interseismic coupling along the Xianshuihe-Xiaojiang fault system, eastern Tibet. Geophys J Int 228:1361-1372. https://doi.org/10.1093/gji/ggab403

Li YX, Bürgmann R (2021) Partial coupling and earthquake potential along the Xianshuihe Fault China. J Geophys Res Solid Earth. https://doi.org/10. 1029/2020JB021406

Li LY, Ji LY, Li YJ, Wei Z (2016) Current activity characteristics of Xianshuihe fault zone and its relationship with strong earthquakes based on fault-crossing measurements. Acta Seism Sin 38(5):739-750. https://doi.org/10. 11939/jass.2016.05.008

Liang HB, Zhan W, Li JW (2021) Vertical surface displacement of mainland China from GPS using the multisurface function method. Adv Space Res 68(12):4898-4915. https://doi.org/10.1016/j.asr.2021.02.024

Liang H, Wu Y, Chen C, Xiong W (2018) Coseismic displacement and dislocation inversion of 2014 Yutian M(s)73 earthquake in Xinjiang. Chin J Geophys 61(12):4817-4826. https://doi.org/10.6038/cjg2018M0065

Liu QY, Van Der Hilst RD, Li Y, Yao HJ, Chen JH, Guo B, Qi SH, Wang J, Huang H, Li SC (2014) Eastward expansion of the Tibetan Plateau by crustal flow and strain partitioning across faults. Nat Geosci 7(5):361-365. https://doi.org/ 10.1038/ngeo2130

Luo G, Liu M (2018) Stressing Rates and Seismicity on the Major Faults in Eastern Tibetan Plateau. J Geophys Res Solid Earth 123:10968-10986. https:// doi.org/10.1029/2018JB015532

Maurin T, Masson F, Rangin C, Min UT, Collard P (2010) First global positioning system results in northern Myanmar: Constant and localized slip rate along the Sagaing fault. Geology 38(7):591-594. https://doi.org/10.1130/ G30872.1

McCaffrey R, Stein S, Freymueller J (2002) Crustal block rotations and plate coupling. Plate Boundary Zones. Geodyn Ser 30:101-122. https://doi.org/ 10.1029/GD030p0101

Meade BJ (2007) Present-day kinematics at the India-Asia collision zone. Geology 35:81-84. https://doi.org/10.1130/G24443C.1

Miura S, Sato T, Tachibana K, Satak Y (2002) Strain accumulation in and around Ou backbone range, northeastern Japan as observed by a dense GPS network. Earth Planets Space 54(11):1071-1076. https://doi.org/10.1186/ BF03353304

Moreno M, Rosenau M, Oncken O (2010) 2010 Maule earthquake slip correlates with pre-seismic locking of Andean subduction zone. Nature 467:198-202. https://doi.org/10.1038/nature09349

Nalbant SS, McCloskey J (2011) Stress evolution before and after the 2008 Wenchuan. China Earthquake Earth Planet Sci Lett 307(1-2):222-232. https://doi.org/10.1016/j.epsl.2011.04.039

Nalbant SS, Hubert A, King GC (1998) Stress coupling between earthquakes in northwest Turkey and the north Aegean Sea. J Geophys Res Solid Earth 103:24469-24486. https://doi.org/10.1029/98JB01491

Navarro A, Ca Talo J, Fernandes R, Miranda M, Bastos L (2003) The Terceira island (Azores) crustal deformations from GPS data. Earth Planets Space 55:637-642. https://doi.org/10.1186/BF03352470

Parsons T, Ji C, Kirby E (2008) Stress changes from the 2008 Wenchuan earthquake and increased hazard in the Sichuan basin. Nature 454:509-510. https://doi.org/10.1038/nature07177

Qian H, Allen C, Luo Z, Wen X, Zhou H, Huang W (1988) The active characteristics of Xianshuihe fault in Holocene. Earthq Res China 4(2):9-18 (CNKI:SU N:ZGZD.0.1988-02-001)

Qiao X, Zhou Yu (2021) Geodetic imaging of shallow creep along the Xianshuihe fault and its frictional properties. Earth Planet Sci Lett 567:117001. https://doi.org/10.1016/j.epsl.2021.117001

Qu W, Lu Z, Zhang Q, Hao M, Wang Q, Qu F, Zhu W (2018) Present-day crustal deformation characteristics of the southeastern Tibetan Plateau and surrounding areas by using GPS analysis. J Asian Earth Sci 163:22-31. https:// doi.org/10.1016/j.jseaes.2018.05.021

Reddy CD, Gamal E-F, Teruyuki K, Seiichi Shimada K, Kumar V (2000) Crustal strain field in the Deccan trap region, western India, derived from gps measurements. Earth Planets Space 52:965-969. https://doi.org/10.1186/BF03352313

Riguzzi F, Crespi M, Devoti R, Doglioni C, Pietrantonio G, Pisani AR (2012) Geodetic strain rate and earthquake size: new clues for seismic hazard studies. Phys Earth Planet Inter 206-207:67-75. https://doi.org/10.1016/j. pepi.2012.07.005 
Savage JC, Burford RO (1973) Geodetic determination of relative plate motion in central California. J Geophys Res Solid Earth 78(5):832-845. https://doi. org/10.1029/JB078i005p00832

Savage JC, Prescott WH (1978) Asthenosphere readjustment and the earthquake cycle. J Geophys Res Solid Earth 83(B7):3369-3376. https://doi.org/10.1029/ JB083iB07p03369

Shan B, Xiong X, Zheng Y, Jin B, Liu C, Xie Z, Hsu H (2013) Stress changes on major faults caused by 2013 Lushan earthquake and its relationship with 2008 Wenchuan earthquake. Sci China (ser D) 56(7):1169-1176. https://doi.org/ 10.1007/s11430-013-4642-1

Shan B, Xiong X, Wang R, Zheng Y, Yadav R (2015) Stress evolution and seismic hazard on the Maqin-Maqu segment of East Kunlun Fault zone from co-, post-and interseismic stress changes. Geophys J Int 200:244-253. https:// doi.org/10.1093/gji/ggu395

Shao Z, Xu J, Ma H, Zhang L (2016) Coulomb stress evolution over the past 200years and seismic hazard along the Xianshuihe fault zone of Sichuan, China. Tectonophysics 670:48-65. https://doi.org/10.1016/j.tecto.2015.12. 018

Stein RS (2003) Earthquake conversations. Sci Am 288:72-79. https://doi.org/10. 1038/scientificamerican0103-72

Stein RS, Barka AA, Dieterich JH (1997) Progressive failure on the North Anatolian fault since 1939 by earthquake stress triggering. Geophys J Int 128:594-604. https://doi.org/10.1111/j.1365-246X.1997.tb05321.x

Su G, Zhan W (2021) Seasonal and long-term vertical land motion in Southwest China determined using GPS, GRACE, and surface loading model. Earth Planets Space 73:131. https://doi.org/10.1186/s40623-021-01459-4

Sun T, Wang K, linuma T, Hino R, He J, Fujimoto H, Kido M, Osada Y, Miura S, Ohta Y, Hu Y (2014) Prevalence of viscoelastic relaxation after the 2011 Tohoku-Oki earthquake. Nature 514(7520):84. https://doi.org/10.1038/nature13778

Tapponnier P, Peltzer G, Dain A, Armijo R, Cobbold P (1982) Propagating extrusion tectonics in Asia: new insights from simple experiments with plasticine. Geology 10(12):611-616. https://doi.org/10.1130/0091-7613(1982)10\% 3c611:PETIAN\%3e2.0.CO;2

Toda S, Lin J, Meghraoui M, Stein RS (2008) 12 May 2008 M=7.9 Wenchuan, China, earthquake calculated to increase failure stress and seismicity rate on three major fault systems. Geophys Res Lett. https://doi.org/10.1029/2008G L034903

Wan Y, Shen ZK (2010) Static Coulomb stress changes on faults caused by the 2008 Mw 7.9 Wenchuan, China earthquake. Tectonophysics 491:105-118. https://doi.org/10.1016/j.tecto.2010.03.017

Wang E, Burchfiel BC, Royden LH, Chen L, Chen J, Li W, Chen Z (1998) Late Cenozoic Xianshuihe-Xiaojiang, Red River, and Dali fault systems of southwestern Sichuan and central Yunnan, China. Geol Soc Am Spec Pap 327:1-108

Wang H, Wright TJ, Biggs J (2009) Interseismic slip rate of the northwestern Xianshuihe fault from InSAR data. Geophys Res Lett 36(3):139-145. https:// doi.org/10.1029/2008GL036560

Wang M, Shen ZK (2020) Present-Day crustal deformation of continental China derived from GPS and its tectonic implications. J Geophys Res Solid Earth 125:e2019JB018774. https://doi.org/10.1029/2019JB018774

Wang X, Xiao J, Xu H, He J (2016) Dynamic responses of the Xianshuihe and Longmenshan fault zones to regional tectonic loading. Chin J Geophys 59:1403-1413. https://doi.org/10.6038/cjg20160421

Wang H, Wright TJ, Liu-Zeng J, Peng L (2019) Strain rate distribution in southcentral Tibet from two decades of InSAR and GPS. Geophys Res Lett. https:// doi.org/10.1029/2019GL081916

Wang M, Shen ZK, Wang YZ, Bürgmann R, Wang F, Zhang PZ, Liao H, Zhang R, Wang Q, Jiang ZS, Chen WT, Hao M, Li Y, Gu T, Tao W, Wang K, Xue L (2021) Postseismic deformation of the 2008 wenchuan earthquake illuminates lithospheric rheological structure and dynamics of eastern tibet. J Geophys Res Solid Earth 126:e2021JB22399. https://doi.org/10.1029/2021JB022399

Ward SN (1994) A multidisciplinary approach to seismic hazard in southern California. Bull Seismol Soc Am 84(5):1293-1309. https://doi.org/10.1785/ BSSA0840051293

Weiss JR, Walters RJ, Morishita Y, Wright TJ, Lazecky M, Wang H et al (2020) Highresolution surface velocities and strain for Anatolia from Sentinel-1 InSAR and GNSS data. Geophys Res Lett 47:e2020GL087376. https://doi.org/10. 1029/2020GL087376

Wen X, Allen C, Luo Z, Qian H, Zhou H, Huang W (1989) Segmentation, geometric features, and their seismotectonic implications for the Holocene Xianshuihe fault zone. Acta Seism Sin 11:362-372 (CNKI:SUN:DZXB.0.1989-04-002)
Wen XZ, Ma SL, Xu XW, He YN (2008) Historical pattern and behavior of earthquake ruptures along the eastern boundary of the Sichuan-Yunnan faultedblock, southwestern China. Phys Earth Planet Inter 168(1-2):16-36. https:// doi.org/10.1016/j.pepi.2008.04.013

Wessel P, Smith WH, Scharroo R, Luis J, Wobbe F (2013) Generic mapping tools: improved version released. Eos Trans Am Geophys Union 94:409-410. https://doi.org/10.1002/2013EO450001

Wu YQ, Jiang ZS, Yang GH, Fang Y, Wang WX (2009) The application and method of GPS strain calculation in whole mode using least-squares collocation in sphere surface. Chin J Geophys 52(7):1707-1711. https://doi.org/10.3969/j. issn.0001-5733.2009.07.005

Wu YQ, Jiang ZS, Yang GH, Wei W, Liu X (2011) Comparison of GPS strain rate computing methods and their reliability. Geophys J Int 185(2):703-717. https://doi.org/10.3969/j.issn.1671-5942.2011.05.005

Wu YQ, Jiang ZS, Liang HB, Pang YJ, Zhu S, Liu C, Chen CY, Li JW (2018) Deformation response of seismogenic faults to the Wenchuan Ms8.0 earthquake: a case study for the southern segment of the Longmenshan fault zone. Remote Sens 10(6):894. https://doi.org/10.3390/rs10060894

Xu R, Stamps DS, Huang SM (2018) GPS derived evolution of strain rate in Sichuan region. Jf Southw Jiaotong Univ. 53:344-350. https://doi.org/10.3969/j.issn. 0258-2724.2018.02.017

Xu XW, Wen XZ, Zheng RZ, Ma WT, Song FM, Yu GH (2003) Pattern of latest tectonic motion and its dynamics for active blocks in Sichuan-Yunnan region, China. Sci China (ser D) 46:210-226. https://doi.org/10.3321/j.issn: 1006-9267.2003.z1.017

Xu XW, Wen XZ, Han ZJ, Chen GH, Li CY, Zheng WJ, Zhang SM, Ren ZQ, Xu C, Tan XB (2013) Lushan Ms7.0 earthquake: a blind reserve-fault event. Chin Sci Bull 58:3437-3443. https://doi.org/10.1007/s11434-013-5999-4

Yi GX, Wen XZ, Su YJ (2008) Study on the potential strong-earthquake risk for the eastern boundary of the Sichuan-Yunnan active faulted-block, China. Chin J Geophys 51(6):719-1725. https://doi.org/10.3321/j.issn:0001-5733.2008. 06.012

Yi G, Long F, Wen X, Liang M, Wang S (2015) Seismogenic structure of the M63 Kangding earthquake sequence on 22 Nov. 2014, Southwestern China. Chin J Geophys 58(4):1205-1219. https://doi.org/10.6038/cjg20150410

Zhang P (2008) Present tectonic deformation, strain distribution and deep dynamic process in west of Sichuan, eastern margin of the Tibetan Plateau. Sci China (ser D) 38:1041-1056. https://doi.org/10.1360/zd2008-38-9-1041

Zhang X, Sagiya T (2017) Shear strain concentration mechanism in the lower crust below an intraplate strike-slip fault based on rheological laws of rocks. Earth Planets Space 69(1):82. https://doi.org/10.1186/s40623-017-0668-5

Zhang P, Deng Q, Zhang G, Ma J, Gan W, Min W, Mao F, Wang Q (2003) Active tectonic blocks and strong earthquakes in the continent of China. Sci China (ser D) 46:13-24. https://doi.org/10.1360/03dz0002

Zhang L, Cao D, Zhang J, Sui L (2019) Interseismic Fault Movement of Xianshuihe Fault Zone Based on Across-Fault Deformation Data and InSAR. Pure Appl Geophys 176:649-667. https://doi.org/10.1007/s00024-018-1989-4

Zhao J, Jiang ZS, Niu AF, Liu J, Wu YQ, Wei WX, Liu XX, Yan W (2015) Study on dynamic characteristics of fault locking and fault slip deficit in the eastern boundary of the Sichuan-Yunnan rhombic block. Chin J Geophys 58(3):872-885. https://doi.org/10.6038/cjg20150316

Zhao J, Ren J, Jiang Z, Yue C (2018) Three-dimensional deformation characteristics of the Xianshuihe Fault Zone. Seismol Geol 40(4):818-831. https://doi. org/10.3969/j.issn.0253-4967.2018.04.007

Zhao J, Ren J, Liu J, Liu X, Liang H, Niu A, Yue C, Yuan Z (2020) Coupling fraction and relocking process of the Longmenshan Fault Zone following the 2008 Mw7.9 Wenchuan earthquake-ScienceDirect. J Geodyn. https://doi.org/10. 1016/j.jog.2020.101730

Zhu AL, Xu XW, Zhou YS, Yin JY, Gan WJ, Chen GH (2005) Relocation of small earthquakes in Western Sichuan, China and its implications for active tectonics. Chin J Geophys 48(3):692-700. https://doi.org/10.3321/j.issn: 0001-5733.2005.03.021

Zou ZY, Jiang ZS, Wu YQ, Wei WX, Liu XX (2015) Dynamic characteristics of crustal movement in north-south seismic belt from GPS velocity field before and after the Wenchuan Earthquake. Chin J Geophys 58(5):1597-1609. https:// doi.org/10.6038/cjg20150512

\section{Publisher's Note}

Springer Nature remains neutral with regard to jurisdictional claims in published maps and institutional affiliations. 